
nolepis diminuta. Ivermectin. Levamisole. Mebendazole. Microtubule. Mitochondria. Nitrobenzylthioinosine. Oxamniquine. Oxidative phosphorylation. Permease. Phosphofructokinase. Praziquantel. Protofilament. Rafoxanide. Schistosoma. Tubercidin. Tubulin.

Mots-clés : Antimonies. Ascaris. ATP. Caenorhabditis elegans. Calcium. Récepteurs cholinergiques. Closantel. ADN. Fasciola hepatica. Fumarate réductase. GABA. Hycanthone. Hymenolepis diminuta. Ivermectine. Levamisole. Mebendazole. Microtubule. Mitochondrie. Nitrobenzylthioinosine. Oxamniquine. Phosphorylation oxydative. Perméase. Phosphofructokinase. Praziquantel. Protofilament. Rafoxamide. Schistosoma. Tubercidine. Tubuline.

\title{
STUDIES OF THE MODE OF ACTION OF ANTHELMINTIC DRUGS: TOOLS TO INVESTIGATE THE BIOCHEMICAL PECULARITIES OF HELMINTHS
}

\author{
H. VANDEN BOSSCHE
}

SUMMARY

An overview is given of the results from mode of action studies which improved our knowledge of some biochemical and/or electrophysiological aspects of parasitic helminths. Studies of the molecular mechanism of action of for example, antimonials, pipera- zine, levamisole, ivermectine, salicylanilides, praziquantel, benzimidazolecarbamates, oxamniquine and hycanthome offered tools to learn more of the parasites and their hosts.

RÉsumé : Les études sur les mécanismes d'action des anthelmintiques : instruments pour l'analyse des particularités des helminthes.

Un certain nombre d'acquisitions anciennes et nouvelles dans la connaissance de la biochimie et de l'électro-physiologie des helminthes sont passées en revue à partir des données obtenues lors des études sur les mécanismes d'action. Cette revue sommaire a permis de souligner l'importance des anthelmintiques tels que les dérivés de l'antimoine, la pipérazine, le lévamisole, l'ivermectine, les salicylanilides, le praziquantel, les bezimidazole-carbamates, l'oxamniquine et l'hycanthone, pour l'analyse des particularités des helminthes.
Mode of action studies might tell us how a chemical compound interferes with a target in the parasite and changes the host-parasite interplay. These studies also might highlight differences between the organisms and thus improve our knowledge of the biochemical systems in host and parasite. Already in 1878, Claude Bernard considered pharmacologically active compounds as « instruments well suited for dissecting one by one the properties of the elements of the living organisms ».

The battery of anti-microbial agents that became available opened the way to a better understanding of binding sites and active targets (Gale et al., 1981). Antifungal agents such as the polyenes and imidazole and triazole derivatives

Department of Comparative Biochemistry, Janssen Research Foundation, Turnhoutseweg, 30, B 2340 Beerse, Belgium. are of great help in the study of the distribution and role of sterols in fungal and protozoan membranes (Bolard, 1986; Vanden Bossche, 1990). Azole antifungals triggered the studies on fungal cytochrome P450 and contributed to the identification of new opportunities for prostate and breast cancer therapy (Vanden Bossche et al., 1990).

What do we know on the mode of action of anthelmintics? Do these studies also provide guidance for future research?

\section{INTERFERENCE WITH CARBOHYDRATE METABOLISM}

Investigations using trivalent antimonials, the oldest group of compounds used in antischistosomal therapy, have been of great help in elucidating schistosomal glycolysis. Already in the early fifties Ernest Bueding and Tag Mansour showed that the activity of schistosomal phosphofructokinase (PFK) 
is inhibited by low concentrations of antimonials (Bueding, 1972). Of great interest is the fact that the reduced glycolytic rate, resulting from inhibition of PFK, could be reversed by the addition of purified mammalian phosphofructokinase. These studies proved that PFK is a key regulatory enzyme in glycolysis, that the mammalian enzyme is much less sensitive (70-80 times) to the antimonials and that schistosomal PFK might be an excellent target for the development of new antischistosomal drugs. However, none of the currently used modern anthelmintics has PFK as target.

Although levamisole inhibits the fumarate reductase in nematodes at relatively high concentrations only, the results obtained pinpoint the fumarate reductase complex as another possible target for anthelmintics.

Salicylanilides such as, closantel and rafoxanide, are potent fasciolicides. Their activity has been linked to their capacity to uncouple mitochondrial electron-transport associated phosphorylation. For example, 12 hours after i.m. treatment of the sheep host with $5 \mathrm{mg}$ closantel $/ \mathrm{kg}$ body weight the ATP content of Fasciola hepatica was decreased by more than $60 \%$ and the adenylate energy charge was 0.53 instead of the 0.84 found in liver flukes from control sheep (Vanden Bossche, 1985a). No effect on the oxidative phosphorylation was found in mitochondria isolated from livers of uninfected rats and from hearts of rats, infected and uninfected, 4 and 16 hours after i.m. injection with $5 \mathrm{mg}$ closantel per $\mathrm{kg}$ (Vanden Bossche et al., 1980). Studies with closantel offered examples of possibilities to learn more about Fasciola hepatica and Schistosoma mansoni. Indeed, studies to measure the effects of closantel on liver mitochondria from rats infected with Fasciola revealed that the mitochondria from untreated rats were uncoupled (Vanden Bossche et al., 1983). This uncoupling might be induced by a product(s) excreted by the liver fluke (Vanden Bossche, 1985b). Treatment of the rats with closantel resulted in a normalization of the mitochondrial activity. These Fasciola-induced alterations of liver mitochondria might be involved in the pathology of fascioliasis. Studies on the effects of closantel on $S$. mansoni were suggestive of a role for aerobic metabolism in the generation of energy required by $S$. mansoni for motility (Vanden Bossche, 1985b). These findings indicate that $S$. mansoni might derive a considerable part of their energy from mitochondrial oxidative phorphorylation instead of from glycolysis only.

\section{EFFECTS ON NEUROMUSCULAR SYSTEMS}

Piperazine, one of the first effective anthelmintics, initiated important studies on the neuromuscular system of Ascaris (for a review see Martin, 1987). It has been shown that piperazine acts as an agonist at the extrasynaptic GABA receptor on Ascaris muscle. This increases the $\mathrm{Cl}^{-}$conductance of the membrane and hyperpolarizes muscle cells.
It is of interest that piperazine does not act on rat sympathetic neurons.

A more recently developed nematocide, ivermectin, also paralyzes nematodes by activating membrane chloride conductance in neurons of the nerve cord (see Rew and Fetterer, 1986). This might originate from stimulation of the presynaptic release of GABA. The selectivity might result from the inability of ivermectin to reach its target in the host central nerves system. This highlights the importance of pharmacokinetic studies in both parasite and host.

Levamisole causes a spastic contraction of nematode muscle by acting as a potent agonist at acetylcholine receptors on muscle bag membranes of Ascaris suum. Lewis et al. (1980) showed that levamisole-resistant strains of Caenorhabditis elegans lack normal cholinergic receptors. The latter studies not only suggest that nematodal acetylcholine receptors are targets for levamisole but also focus attention on the small free-living nematode $C$. elegans. This nematode and levamisole have contributed to genetic studies of the nervous system in nematodes (Lewis et al., 1980).

\section{INTERACTION WITH LIPID MEMBRANES}

Praziquantel has broad spectrum activity against cestodes and many trematodes. This pyrazinoisoquinoline derivative also induces next to a rapid muscle contraction, vacuolization of the tegument, followed by a pronounced structural disruption of the parasite's tegument (for a review see Vanden Bossche, 1985a). The molecular mechanism underlaying both the tegumental alterations and muscle contraction are not well understood. However, from the mode of action studies we learned that muscle contraction in Hymenolepis diminuta muscle depends on endogenous $\mathrm{Ca}^{2+}$, whereas muscle contraction in schistosomes is dependent on the influx of external $\mathrm{Ca}^{2+}$. The combined use of a theoretical approach and experimental procedures (such as IR spectroscopy) (Schepers et al., 1988) established the lipid destabilizing capacity of praziquantel. This capacity has been explained in terms of the high praziquantel interaction and the large area occupied per drug molecule in the lipid layer. It should be mentioned that praziquantel does not modify the lipid structure but act as a spacer between lipid molecules. This opens new perspectives in the search for anthelmintics. However, it might be difficult to find compounds that insert selectively into parasite membranes.

As already mentioned, one of the early morphological results of praziquantel treatment is disruption of the integrity of the tegument. The membrane over tubercles on the $S$. mansoni male dorsal surface is damaged and an increase in parasite-specific antigenicity is observed after in vitro treatment (Harnet and Kusel, 1986). Studies of Doenhoff (1989) revealed that the schistocidal activity of praziquantel was enhanced by the synergistic action of 
rabbit antisera. These antisera reacted most intensively in indirect immunofluorescence with the dorsal tubercles of drug-treated male worms. Further studies indicated that only selected antigens which are exposed through drug damage may be sensitive to immune attack (Doenhoff, 1989). These studies highlight the importance of multidisciplinary studies on the immune-dependence of chemotherapy.

\section{Microtubules AS TARGET ORganelles}

The introduction of benzimidazole carbamates, such as mebendazole, not only improved anthelmintic chemotherapy but also triggered the study of both helminth and mammalian tubulin. For example, studies of Gull et al. (1987) showed that the supramolecular structure of helminth microtubules varies both between helminths and even between different cell types in the same helminth. However in no case they discovered helminth microtubules with 13 protofilaments as found in most other organisms, including mammals. This unusual supramolecular structure of helminth microtubules might be involved in the selective action of benzimidazoles on helminth microtubules in vivo (Gull et al., 1987).

\section{NUCLEIC ACID PRECURSOR ANALOGUES}

Schistosomes lack the ability to synthesise purines de novo and rely on salvage pathways for their purine requirements. As a result, purine analogues are effective antischistosomals. However, nucleic acid precursor analogues are often toxic to man and this seriously restricts their clinical use. El Kouni et al. (1987) have demonstrated that it is possible by using a nucleoside transport inhibitor to restrict their effect on the host. For example, 8-deazaadenosine (tubercidin) is an effective inhibitor of Schistosoma mansoni but is also toxic to the host. The selectivity of this compound is improved by simultaneous administration of a specific nucleosid transport inhibitor, nitrobenzylthioinosine. This inhibitor effectively blocks nucleoside transport into mammalian cells, but is ineffective in preventing uptake of tubercidin into $S$. mansoni and S. japonicum. This approach does raise some very interesting possibilities with regard to the use of toxic drugs in chemotherapy. If these drugs are normally illicitly transported into cells by a preexisting permease, then selective inhibition of the host's permeases by a non-penetrant inhibitor will be effective in achieving a therapeutic advantage.

\section{DNA AS TARGET FOR ANTHELMINTICS}

Oxamniquine has excellent activity against $S$. mansoni but has virtually no activity against other schistosomes. It differentialy kills the male worm. Oxamniquine was found to bind in significant amounts to DNA of male schistosomes, much less to DNA of the female partner and almost not to DNA of oxamniquine resistant worms (PicaMattoccia et al., 1987). Similar results were obtained with hycanthone. There is evidence that the latter drug is converted into an alkylating agent by drug esterification followed by ester dissociation and the formation of a charged moiety which could easily alkylate macromolecules. Hycanthone resistance might originate from the absence of drugesterifying activity. At the moment it is still an open question whether this conversion into an active ester is also involved in the antischistosomal properties of oxamniquine. However, the studies with hycanthone highlight the importance of metabolism studies in the parasite to understand the molecular basis of anthelmintic action.

\section{CONCLUSION}

The few anthelmintics discussed in this paper prove that mode of action studies generate a lot of questions and a few answers only. Nevertheless, these studies triggered interest in for example the electrophysiological, biochemical and molecular biological aspects of parasites and thus opened the possibility for a multi-disciplinary approach to improve treatment of parasitic diseases.

\section{REFERENCES}

Bernard C. : La science expérimentale. Ballière, Paris, 1878.

Bolard J. : How do polyene macrolide antibiotics affect the cellular membrane properties? Biochim. et Biophys. Acta, 1986, 864, 257-304.

Bueding E. : Biochemical effects of antischistosomal drugs. In : Vanden Bossche H. (ed.) Comparative Biochemistry of Parasites. Academic Press, New York, 1972, 25-32.

Doenhoff M. J. : The immune-dependence of chemotherapy in experimental schistosomiasis. Mem. Inst. Oswaldo Cruz, 1989, 84, suppl. 1, 31-37.

El Kouni M. H., Cha S. : Metabolism of adenosine analogues by Schistosoma mansoni and the effect of nucleotide transport inhibitors. Biochem. Pharmacol., 1987, 36, 1099-1106.

Gale E. F., Cundliffe E., Reynolds P. E., Richmond P. E., Warring M. J. : The Molecular Basis of Antimycotic Action. John Willey and Sons, London, 1981.

Gull K., Dawson P. J., Davis C., Bayard E. H. : Microtubules as target organelles for benzimidazole anthelmintic chemotherapy. Biochem. Soc. Trans., 1987, 15, 59-60.

Harnet W., Kusel J. : Increased exposure of parasite antigens at the surface of adult male Schistosoma mansoni exposed to praziquantel in vitro. Parasitology, 1986, 93, 401-405.

Lewis J. A., Wu C. H., Levine J. H., Berg H. : Levamisoleresistant mutants of the nematode Caenorhabditis elegans appear to lack pharmacological acetylcholine receptors. Neuroscience, 1980, 5, 967-989.

Martin R. J. : The $\gamma$-aminobutyric acid receptor of Ascaris as a target for anthelmintics. Biochem. Soc. Trans., 1987, 15, 61-65.

Pica-Mattoccia L., Cioli D., Archer S. : Schistosimicides and DNA functioning. Biochemical Society Transactions, 1987, 15, 70-73. 
Rew R. S., Fetterer R. H. : Mode of action of antinematodal drugs. In : Campbell W. C. and Rew R. S. (eds). Chemotherapy of Parasitic Diseases. Plenum Press, New York, 1986, 321-337.

Schepers H., Brasseur R., Goormaghtigh E., Duquenoy P., Ruysschaert J. M. : Mode of insertion of praziquantel and derivatives into lipid membranes. Biochem. Pharmacol., 1988, 37, 1615-1623.

Vanden Bossche H. : Pharmacology of anthelmintics. In : Vanden Bossche H., Thienpont D. and Janssens P. G. (eds). Chemotherapy of Gastrointestinal Helminths. Springer-Verlag, Berlin, $1985 a, 125-181$.

Vanden Bossche $\mathrm{H}$. : How anthelmintics help us to understand helminths. Parasitology, 1985b, 90, 675-685.

Vanden Bossche H. : Importance and role of sterols in fungal membranes. In : Kuhn P. J., Trinci A. P. J., Jung M. J.,
Goosey M. W. and Copping L. G. (eds.), Biochemistry of Cells Walls and Membranes in Fungi. Springer-Verlag, Berlin, 1990, 135-157.

Vanden Bossche H., Verhoeven H., Lauwers H. : Uncoupling of liver mitochondria associated with fascioliasis in rats - normalisation by closantel. In : Vanden Bossche H. (ed.). The Host Invader Interplay. Elsevier/North-Holland Biomedical Press, Amsterdam, 1980, 699-704.

Vanden Bossche H., Verheyen A., Verhoeven H., Arnouts D. : Alterations in rat liver mitochondria caused by Fasciola hepatica. Contrib. to Microbiol. Immunol., 1983, 7, 30-38.

Vanden Bossche H., Willemsens G., Bellens D., Roels I., Janssen P. A. J. : From $14 \alpha$-demethylase inhibitors in fungal cells to androgen and oestrogen biosynthesis inhibitors in mammalian cells. Biochem. Soc. Trans., 1990, 18, 10-13. 